\title{
The effects of atrium on energy performances of office buildings according to Turkish climate regions
}

\author{
S.G. Koç*, S. Maçka Kalfa \\ Karadeniz Technical University, Department of Architecture, Trabzon, Turkey
}

\begin{abstract}
Nowadays, the atrium is designed to provide more daylight to the interior and to reduce heating, cooling and total energy loads of buildings. Optimum atrium design can reduce the total energy consumption of a building by reducing artificial lighting loads that greatly affect the heating and cooling energy load. Many parameters are effective in optimum atrium design for building energy performance. These are atrium type, aspect ratio (length to width), height, and preferred glazing types and shading devices on atrium facades. The goal of the study is to assess the impact of these parameters on the building total energy loads and to identify the most energy-efficient atrium design. For this goal, a hypothetical reference office building model is designed. Three office building models were created with the addition of a central courtyard, a central atrium and a semi-closed atrium on the reference office building. It was tested five different double-glazing systems, two window-to-wall ratio, and horizontal louvre shading device on these four office models according to climate regions. All of the models were simulated in DesignBuilder energy simulation software using climatic data of İzmir (hot-humid), Trabzon (moderate-humid) and Ankara (cold) provinces representing primary climatic regions of Turkey. Obtained results were evaluated according to annual heating, cooling and total energy loads according to the climate regions. As a result, the office building model (Model 1) with the central courtyard showed the highest performance in terms of total energy loads in moderate-humid and hot-humid climates. As for the cold climate, Model 3 with semi-closed atrium shows the best performance.
\end{abstract}

\section{Keywords}

Energy performance; Office building; Atrium; Energy simulation; Climate region

Received: 03 August 2019; Accepted: 13 September 2019

ISSN: 2630-5771 (online) (C) 2019 Golden Light Publishing All rights reserved.

\section{Introduction}

As is known, the use of non-renewable energy resources, which causes economic and environmental damages worldwide, is increasing day by day. The building sector has a significant share in the use of these resources and accounts for about $30 \%$ of the global final energy use. The International Energy Agency foresees that the energy consumption rate in the building sector will increase by $50 \%$ by 2050 unless measures are taken to reduce the consumption in the sector [1]. Therefore, energy-efficient measures should be taken in the buildings especially at the early design stage. The critical point is to maintain comfort conditions while reducing energy consumption. Lighting energy consumption in commercial buildings where high lighting levels are required due to activity needs total energy consumption has a significant share. For this reason, it is necessary to apply design approaches to reduce this

* Corresponding author

Email: senagoknurkoc@ktu.edu.tr 
consumption by increasing the amount of natural daylight reaching the inside of the building. The use of atrium is one of the most effective of these approaches. While the atrium provides aesthetic advantages to a building, it also positively affects the user psychology due to its daylight transmission [2]. However, the large glass surfaces used in the atrium are highly influenced by the external thermal conditions due to the high solar energy transmittance $[3,4,5]$. Therefore, the use of the atrium can affect the heating and cooling energy demand differently [6]. If the design of an atrium is properly applied (according to the shape, height, aspect ratio, glazing types, shading devices) total energy consumption, including heating and cooling energy consumption, can be reduced by taking special measures $[7,8]$.

Numerous researchers have investigated the effect of atrium use on building energy consumption in recent years. Aldawoud [9] researched the most energy-efficient atrium design, researching the effect of the atrium of different shapes and geometries on total building energy consumption under various conditions. Huang et al. [10] questioned the effect of double atrium use on building lighting energy consumption and indoor daylighting according to shape, spacing, position and area parameters. Vujošević and KrstićFurundžić [11] analyzed the energy performance of a hypothetical model with various atrium design alternatives using the numerical computer simulations. The results of the studies show that when the geometric properties of the atrium are changed, it causes significant changes in energy consumption depending on the climate.

In some studies, in addition to energy consumption research, the effect of ventilation has been also evaluated. Lan et al. [12] conducted CFD simulation and field measurement to investigate the relationship between atrium geometry and energy consumption in cold climate, China. Moosavi et al. [13] mentioned of the importance of crossventilation in its development of the indoor thermal conditions of atriums; In another study [14], the same authors emphasized the importance of the effect of atrium components and configurations on indoor thermal conditions and ventilation behavior, by identifying the most effective parameters, and recommending buoyancy-driven ventilation, especially for hot and humid climates. Pfafferott et al. [15], with passive cooling provided by night ventilation, and Göcer et al. [16] reported that buffer zone behavior and stack effect can improve the indoor comfort level of atriums.

There are also studies investigating the relationship between atrium types and energy consumption. Aldawoud and Clark [17] compared the use of the same geometric proportions of courtyard and atrium for 4 different climate types in terms of energy performance. It was concluded that open courtyard performed better for short buildings and closed atrium was better for longer buildings. At this point, the height of the building varies according to parameters such as glazing type and climate type. Ghafar et al. [18] tested the thermal performance of 5 different atrium types for 4 different climate types according to different skylight positions and tilted angles using 2 simulation programs (to ensure the accuracy of the results). And then calculated the solar intensities for different roof geometries. According to the results of the study, the findings of the two simulation programs confirmed each other, and the solar intensities at the atrium surface significantly affected the atrium's roof geometry and skylight design. Sher et al. [6] investigated energy savings achieved by using atrium in small houses by comparing the 4 basic atrium types with the nonatrium case in a residential building. According to the results of the study, the use of atrium increases the annual heating energy demand of the building and reduces the annual cooling energy demand. Considering the total energy saving, a significant ratio of $15.7 \%$ was achieved annually. Aram and Alibaba [19] analyzed the optimal single-storey office building model with a corner atrium type according to 4 different atrium orientations and 5 different window opening ratios. The results show that for the Mediterranean climate, user comfort and energy efficiency performance throughout the year can be improved, given the atrium orientation and window opening rates. Vethanayagam and 
Abu-Hijleh [20] researched the variables that affect the efficiency of the atrium in terms of thermal and daylight performance and the appropriate values for these variables. As a result of the study, it is seen that when optimum values are applied together for all variables, energy consumption can be reduced by approximately $20 \%$ regardless of the number of floors. In addition to all its advantages, Danielski et al. [21] found that atrium design has the potential to increase the social interaction of building users. Together with this result, the study identified three criteria for atrium design. To increase the energy efficiency of the atrium, shape factor for whole building should be reduced, the glazing area should have minimum space to provide visual comfort conditions, and to prevent unwanted heat gain adjustable shading device should be used on the atrium facade. All these studies show that when optimum values of atrium parameters are determined, significant savings can be achieved in total annual energy consumption, especially by reducing heating and cooling consumption, and that atrial use has significant social benefits for the user.

As mentioned above, there are many studies about atriums, but this issue requires different solutions according to climate type, building type and different parameters. In this study, the impacts of different atrium types, window-to-wall ratio, glazing types and shading devices on the building total energy loads were tried to determine. For this purpose, a hypothetical reference office building was designed and simulated with DesignBuilder energy simulation software using climatic data of representing moderate-humid, hot-humid and cold climate regions of Turkey. The results were evaluated according to annual heating, cooling and total energy loads.

\section{Method}

In this study, a hypothetical office building model with mid-storey was designed as a reference case to determine the energy performance of different atrium types according to different climate regions. Two types of office rooms have been created considering the optimum office room sizes for two people. These are corner office room and interspace office room. There are 4 corner-office and 16 interspace office rooms on each storey in the reference case. In Fig. 1, information of the reference office building model was given as visual and dimensional.

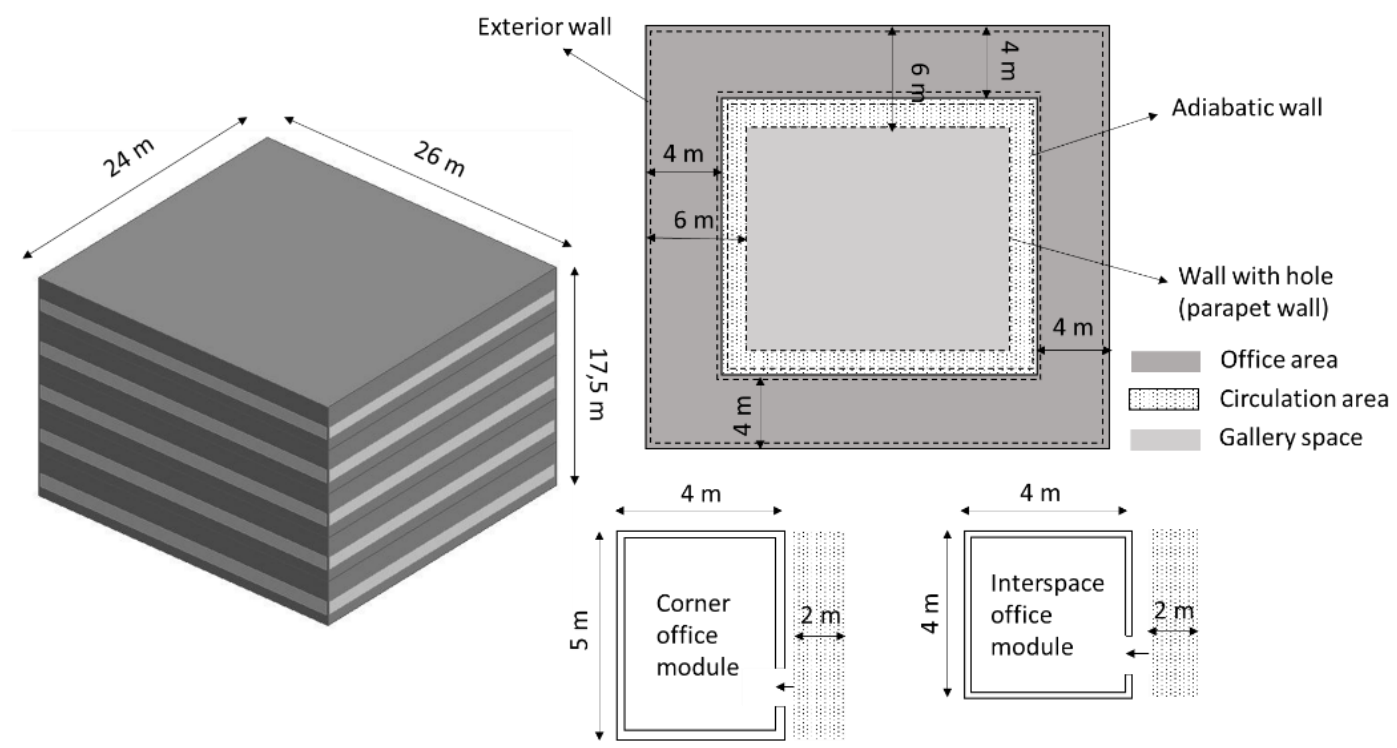

a) Dimensions of the $3 \mathrm{D}$ office module

b) Distributions of zones in the office model plan and the office module types

Figure 1. Information on the reference office model 
As shown in Fig. 1, each storey composed of three zones. These are office area, circulation area, and gallery space. Using this reference case model, three office building models were generated with courtyard and atrium. It was assumed that dimensions of the office rooms and floor area, and the width of the circulation hole were constant. And three models with central courtyard, central atrium and semi-closed atrium were created. In all models, the number and dimensions of the office rooms and the floor area of the atria were changed. In Table 1, dimensional and visual data of three office models were given. 144 scenarios for three office building models and 24 scenarios for the reference office building model depending on many important variables were generated. Variables considered in scenarios were given below.

- Climate; hot-humid (İzmir), moderate-humid (İstanbul), cold (Ankara)

- Window-to-wall ratio; $50 \%$ and $100 \%$

- Double glazing types; clear, Low-E coated, reflective and selective-permeable glazing

- Shading device type of atriums; horizontal louvre

The opaque wall construction of all building models was selected concrete. Thermophysical and dimensional properties of using glazing types were shown in Table 2. All scenarios were simulated using DesignBuilder energy simulation program. Require data for simulation were summarized in Table 3 .

Table 1. Dimensional and visual data of courtyard and atriums

\begin{tabular}{|c|c|c|c|}
\hline & $\begin{array}{l}\text { Model } 1 \\
\text { central courtyard }\end{array}$ & $\begin{array}{l}\text { Model } 2 \\
\text { central atrium }\end{array}$ & $\begin{array}{l}\text { Model } 3 \\
\text { semi-closed atrium }\end{array}$ \\
\hline Plan section & & & \\
\hline Atrium dimension (width $\mathrm{x}$ length) & $12 \times 14 \mathrm{~m}$ & $12 \times 14 \mathrm{~m}$ & $14 \times 18 \mathrm{~m}$ \\
\hline Floor area of atrium & $168 \mathrm{~m}^{2}$ & $168 \mathrm{~m}^{2}$ & $252 \mathrm{~m}^{2}$ \\
\hline Floor area of office building & $624 \mathrm{~m}^{2}$ & $624 \mathrm{~m}^{2}$ & $624 \mathrm{~m}^{2}$ \\
\hline Height of office building & $17.5 \mathrm{~m}$ & $17.5 \mathrm{~m}$ & $17.5 \mathrm{~m}$ \\
\hline Ratio (width x length) & $1 \times 1.16$ & $1 \times 1.16$ & $1 \times 1.28$ \\
\hline $\begin{array}{l}\text { Number of office room for each } \\
\text { storey }\end{array}$ & $\begin{array}{l}4 \text { corner office } \\
16 \text { inter-sp. office }\end{array}$ & $\begin{array}{l}4 \text { corner office } \\
16 \text { inter-sp. office }\end{array}$ & $\begin{array}{l}4 \text { corner office } \\
12 \text { inter-sp. office }\end{array}$ \\
\hline Number of occupants for each storey & 40 & 40 & 32 \\
\hline
\end{tabular}

Table 2. Thermophysical and dimensional properties of double glazing units

\begin{tabular}{lllllll}
\hline Glazing type & Thickness $(\mathrm{mm})$ & Gas & $\mathrm{Ug}\left(\mathrm{W} / \mathrm{m}^{2} \mathrm{~K}\right)$ & $\mathrm{SHGC}$ & $\mathrm{T}_{\text {sol }}$ & $\mathrm{T}_{\text {vis }}$ \\
\hline DCLR & $6 / 12 / 6$ & Air & 2.7 & 0.70 & 0.62 & 0.79 \\
DLOWE\#2 & $6 / 12 / 6$ & Air & 1.6 & 0.41 & 0.36 & 0.70 \\
DGR & $6 / 12 / 6$ & Air & 2.7 & 0.42 & 0.30 & 0.59 \\
DREF & $6 / 12 / 6$ & Air & 2.7 & 0.27 & 0.18 & 0.26 \\
DSSL & $6 / 12 / 6$ & Air & 1.6 & 0.30 & 0.27 & 0.63 \\
\hline
\end{tabular}


Table 3. Require input data for simulation

\begin{tabular}{|c|c|c|}
\hline HVAC system & VAV system & \\
\hline \multirow[t]{3}{*}{ Heating } & Fuel & Natural gas \\
\hline & Set-point temperature $\left({ }^{\circ} \mathrm{C}\right)$ & 20 \\
\hline & Set-back temperature $\left({ }^{\mathrm{O}} \mathrm{C}\right)$ & 18 \\
\hline \multirow[t]{3}{*}{ Cooling } & Fuel & Electric \\
\hline & Set-point temperature $\left({ }^{\circ} \mathrm{C}\right)$ & 26 \\
\hline & Set-back temperature $\left({ }^{\mathrm{O}} \mathrm{C}\right)$ & 28 \\
\hline \multirow[t]{3}{*}{ Domestic hot water } & Fuel & Natural gas \\
\hline & Delivery temperature $\left({ }^{\mathrm{O}} \mathrm{C}\right)$ & 65 \\
\hline & Consumption rate $\left(1 / \mathrm{m}^{2}\right.$-day $)$ & 0.02 \\
\hline \multirow[t]{3}{*}{ Ventilation } & Natural ventilation & None \\
\hline & Mechanic ventilation & VAV system \\
\hline & Infiltration coefficient (ach) & 0.5 \\
\hline \multirow[t]{3}{*}{ Lighting } & Type & LED-surface mount \\
\hline & Power density (W/m2-100 lux) & 2.5 \\
\hline & Target illuminance (lux) & 500 \\
\hline Equipment & Power density $\left(\mathrm{W} / \mathrm{m}^{2}\right)$ & Computer for two:5.4; Printer for two: 2.22 \\
\hline \multirow[t]{3}{*}{ Schedules } & Occupant & 08:00-18:00 \\
\hline & HVAC & 07:00-17:00 \\
\hline & Equipment & Computer: 09:00-17:00; Printer: 14:00-15:00 \\
\hline
\end{tabular}

\section{Method}

The simulation results show that usage atrium with different geometry in office buildings is greatly affected total energy loads (heating, cooling and electricity loads). Also, it is seen that this effect ratio changes according to many parameters (climate, glazing types, window-to-wall ratio, shading device type). In the double clear glazed atrium-free and courtyard-free office model (reference), the increases and decreases in total energy load were obtained from the change of the parameters. The effects of the climate on the energy loads were first determined, then the effects of the arrangement of the courtyard, central atrium and semi-closed atrium on the same office building model were investigated. And the performance increase by using the horizontal louver shading device by determining the effect of changing the glazing types on these models.

\subsection{Effects of climate on energy loads}

Each model showed different level performance according to climate region in terms of heating, cooling, and total energy load. In Fig. 2, the comparison of all model's energy loads was given according to climate regions. The highest heating and cooling loads were occurred cold climate and hot-humid climates, respectively. In terms of total energy load, it was found that hot-humid and moderate-humid climate regions have the best performance.

In Table 4, comparing percentage performances of investigated models were given in terms of energy loads according to the reference model for climate regions. Heating load performance was realized the highest ratio in model 3 with semiclosed atrium according to the reference model without atrium in all climates. 

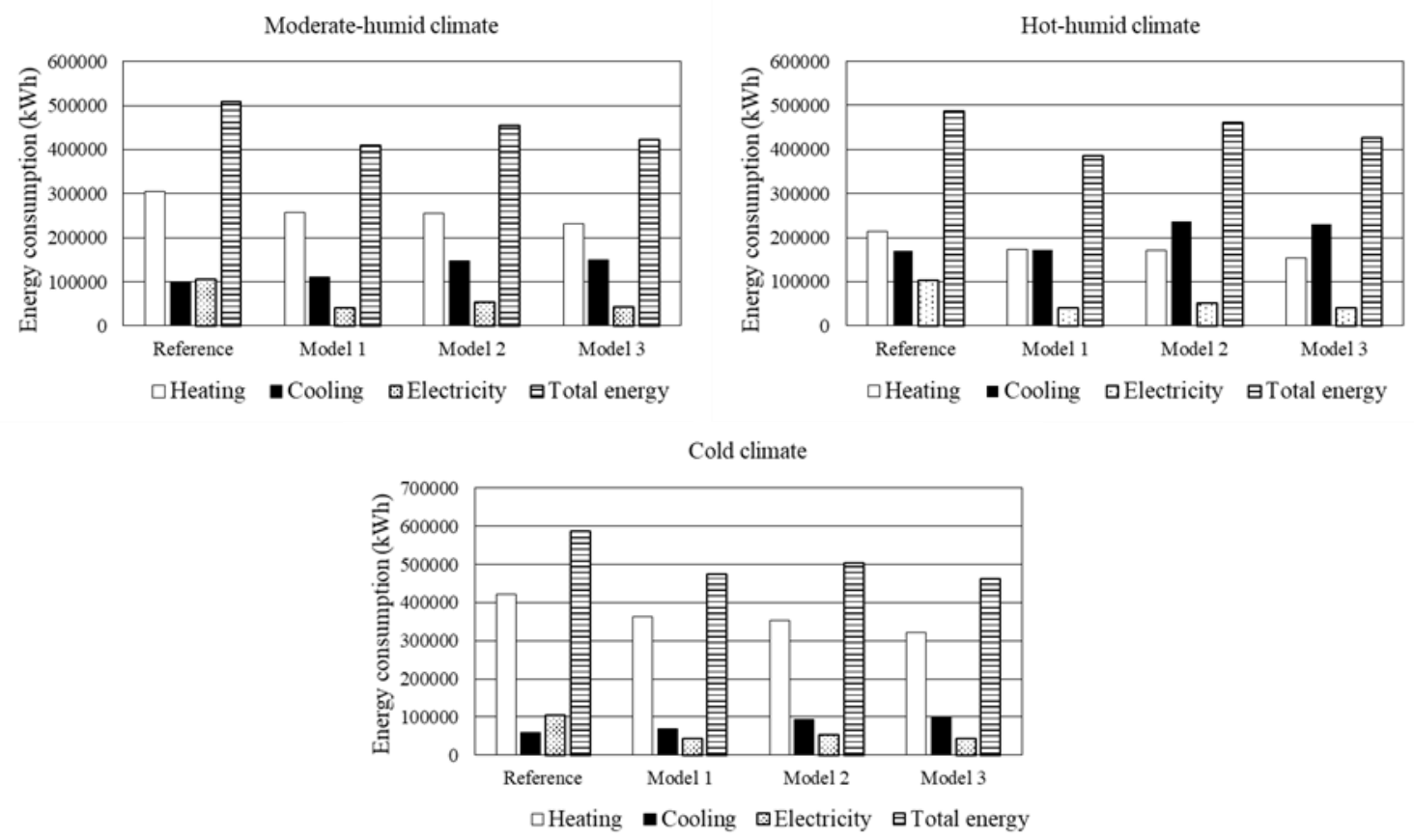

Fig. 2. Energy loads of investigated models according to different climate regions

Table 4. Comparing percentage performances of investigated models in terms of energy loads according to the reference model for climate regions

\begin{tabular}{lllll}
\hline Climate region & & $\begin{array}{l}\text { Heating load } \\
\text { performance }\end{array}$ & $\begin{array}{l}\text { Cooling load } \\
\text { performance }\end{array}$ & $\begin{array}{l}\text { Total energy load } \\
\text { performance }\end{array}$ \\
\hline $\begin{array}{l}\text { Moderate-humid } \\
\text { climate }\end{array}$ & Highest & $+23 \%$, Model 3 & $-11 \%$, Model 1 & $+19 \%$, Model 1 \\
Hot-humid & Lowest & $+15 \%$, Model 1 & $-49 \%$, Model 3 & $+10 \%$, Model 2 \\
climate & Highest & $+28 \%$, Model 3 & $-1 \%$, Model 1 & $+21 \%$, Model 1 \\
& Lowest & $+19 \%$, Model 1 & $-39 \%$, Model 2 & $+5 \%$, Model 2 \\
Cold climate & Highest & $+24 \%$, Model 3 & $-16 \%$, Model 1 & $+21 \%$, Model 3 \\
& Lowest & $+14 \%$, Model 1 & $-63 \%$, Model 3 & $+14 \%$, Model 2 \\
\hline
\end{tabular}

Considering the cooling load performance, all models perform worse than the reference model. Reason of this, total glazing area in Model 1, Model 2 and Model 3 are more than the reference model. As total glazing area increase, internal gains coming from sun increase and this case increase the cooling load. In terms of total energy load performance, in moderate-humid and hot climates, Model 1 shows the best performance. As for the cold climate, Model 3 has the best performance.

According to climate regions, the percentage of heating, cooling and total energy loads vary greatly in all models. Each climate shows different outdoor temperatures throughout the year, which determines if the building needs more heating or cooling. Fig. 3 shows the distribution of energy loads in the reference model according to climate regions. In all climates, total energy loads were found the same. But, heating and cooling loads were obtained as different. The first target in hothumid climates is cooling, while in cold and moderate-humid climates, heating is preferred. 
Moderate-humid climate

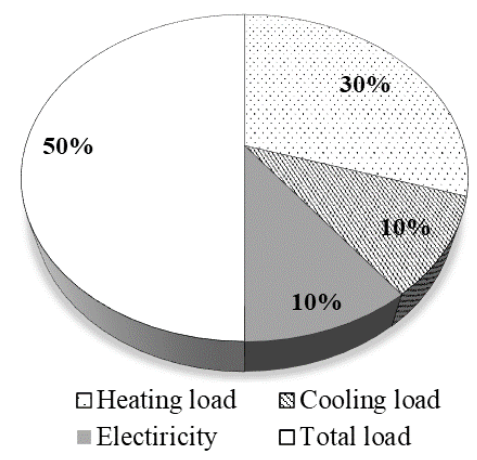

Hot-humid climate

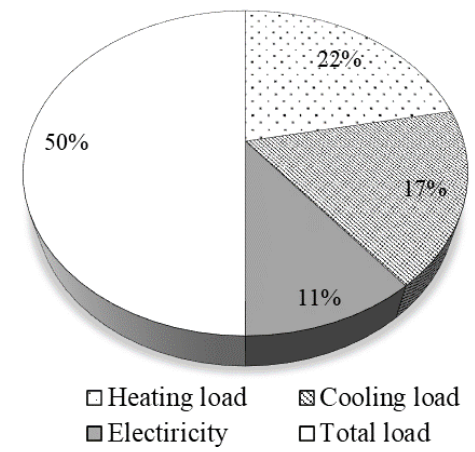

Cold climate

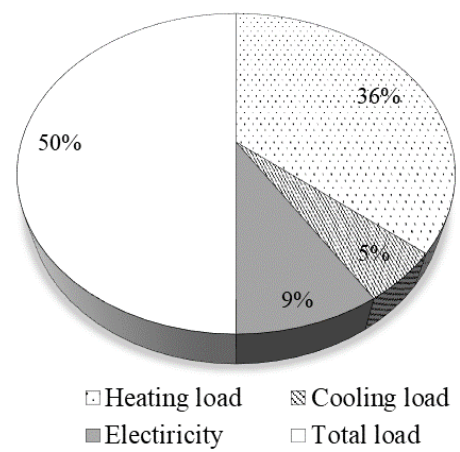

Fig. 3. Energy loads in the reference model according to the climate regions

\subsection{Effects of glazing systems on energy loads}

In all climate regions, after heating, cooling and total energy loads of investigated models are compared with the reference building model with double clear glazing system and determined their energy performances, as the second strategy. It was obtained that effects of usage of heat and solar control double glazing systems on office building models on energy performances of these models considering moderate-humid climate region. Obtained results were summarized in Fig. 4. As you can see from Fig. 4, it was seen that DCLR and DSSL were the best energy performance among all models in terms of the heating load. Because DSSL is the selective-permeable glazing system, it has an efficient role during both heating and cooling periods. In terms of cooling load, DRFL and DSSL showed the highest performance compared to the DCLR that is reference glazing system. Although DLOWE2 and DSSL have a lower performance in terms of heating load, they come into prominence due to their savings in cooling loads based on the total energy load.

From the results of the study, it is seen that the performance increase in the heating load is not achieved in general according to the reference building model with only the change of the glazing system. But, the performance increase obtained in the cooling load is in the range of $27 \%-77 \%$. Thus, the total energy load could be reduced in a great portion that is in the range of $1.4 \%-30 \%$ (Table 5).

\subsection{Effects of window-to-wall ratio on energy loads}

The rise in the window-to-wall ratio increased the transparent surface area of the office models. As a result of this, heating and cooling loads affected in different ratios according to the glazing system type. In Figure 5, energy loads of all office models with DCLR were compared 50\% and $100 \%$ window to wall ratios. Finally, heating and cooling load dramatically increased by $100 \%$ window-to-wall ratio. This increment was observed at different levels in all models. Because of this, all models have the different transparent surface area. However, when Table 5 is examined, it is seen that energy loads through the use of electricity decreased significantly in the models with $100 \%$ window-to-wall ratio where the transparent surface areas were higher. Reason for this, the use of artificial lighting reduced depends on the increased use of natural light.

\subsection{Effects of shading device on energy loads}

In the investigated office models, horizontal shading device has been added to the transparent surfaces of the reference models to conclude to what extent the shading device will change the energy load and increase its performance according to the reference model. In cases where the shading device is not used and the shading device is used, the annual energy loads obtained in all office models are given in Fig. 6. 

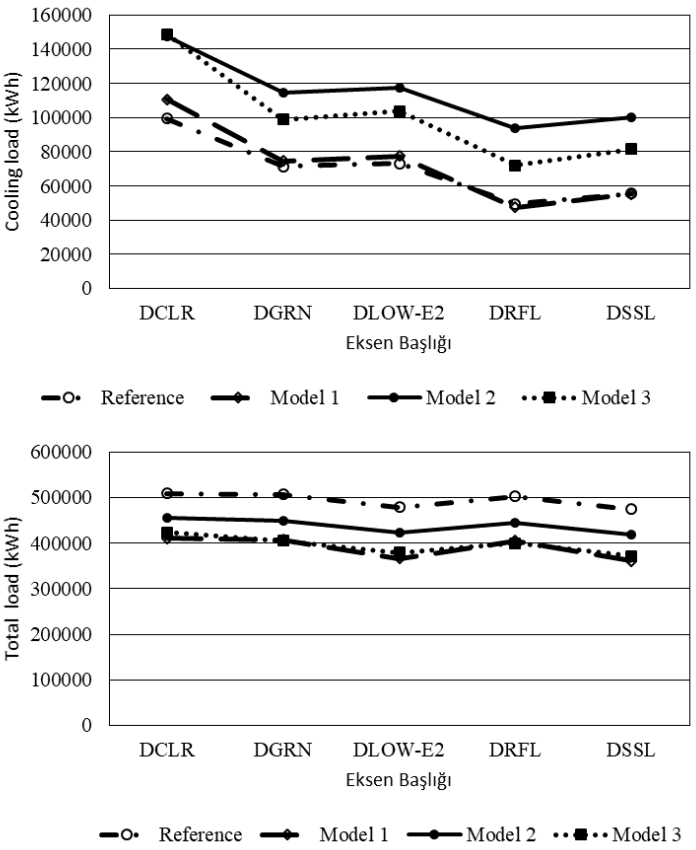

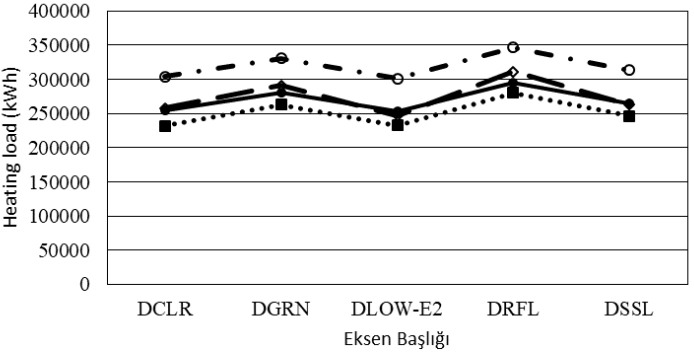

-o. Reference $\rightarrow$ Model $1 \rightarrow$ Model $2 \cdots \cdot$ Model 3

Fig. 4. The heating, cooling and total energy loads of all models according to different double glazing systems

Table 5. Change of models' energy performances through investigated double glazing systems according to the reference models as percentage

\begin{tabular}{llllll}
\hline Total load & DCLR & DGRN & DLOWE2 & DRFL & DSSL \\
\hline Reference & $*$ & $1.4 \%$ & $6 \%$ & $2 \%$ & $7 \%$ \\
Model 1 & $19 \%$ & $20 \%$ & $28 \%$ & $21 \%$ & $30 \%$ \\
Model 2 & $11 \%$ & $12 \%$ & $17 \%$ & $13 \%$ & $18 \%$ \\
Model 3 & $17 \%$ & $21 \%$ & $26 \%$ & $22 \%$ & $27 \%$ \\
Heating load & DCLR & DGRN & DLOWE2 & DRFL & DSSL \\
Reference & $*$ & $-8 \%$ & $-1 \%$ & $-13 \%$ & $-3 \%$ \\
Model 1 & $+16 \%$ & $+5 \%$ & $+19 \%$ & $-2 \%$ & $+14 \%$ \\
Model 2 & $+17 \%$ & $+8 \%$ & $+17 \%$ & $+3 \%$ & $+13 \%$ \\
Model 3 & $+24 \%$ & $+14 \%$ & $+24 \%$ & $+8 \%$ & $+19 \%$ \\
Cooling load & DCLR & DGRN & DLOWE2 & DRFL & DSSL \\
Reference & $*$ & $+29 \%$ & $+27 \%$ & $+51 \%$ & $+45 \%$ \\
Model 1 & $-11 \%$ & $+26 \%$ & $+23 \%$ & $+53 \%$ & $+45 \%$ \\
Model 2 & $-48 \%$ & $-15 \%$ & $-18 \%$ & $-11 \%$ & $-1 \%$ \\
Model 3 & $-49 \%$ & $+1 \%$ & $-4 \%$ & $+28 \%$ & $+18 \%$ \\
\hline
\end{tabular}



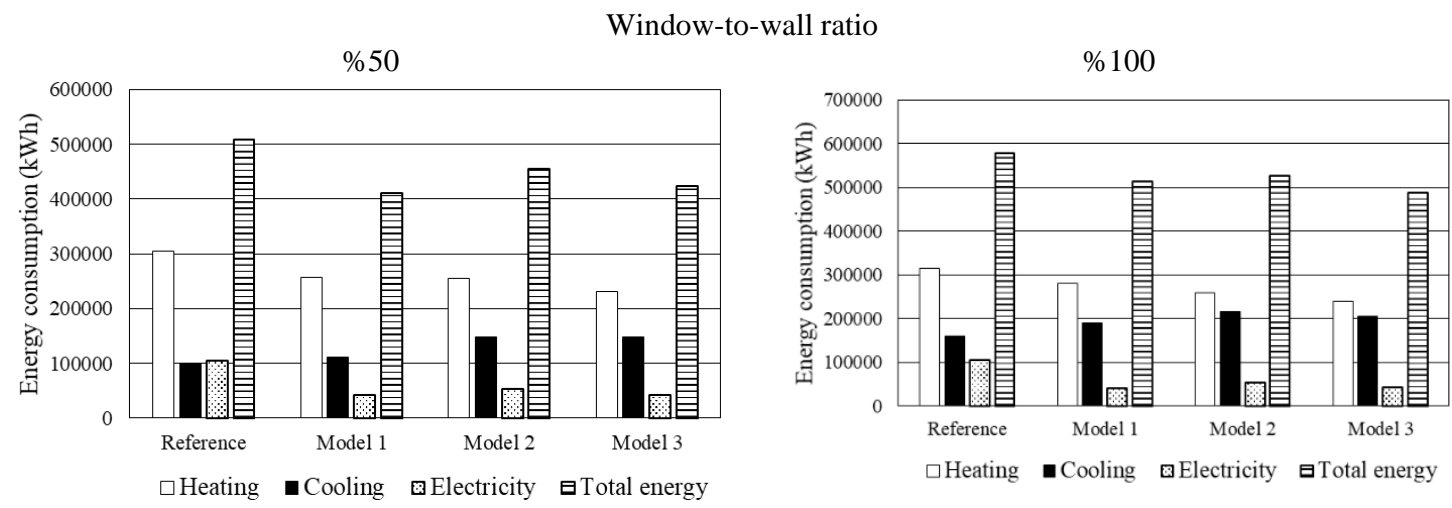

Fig. 5. Comparing energy loads in all models according to window-to-wall ratios

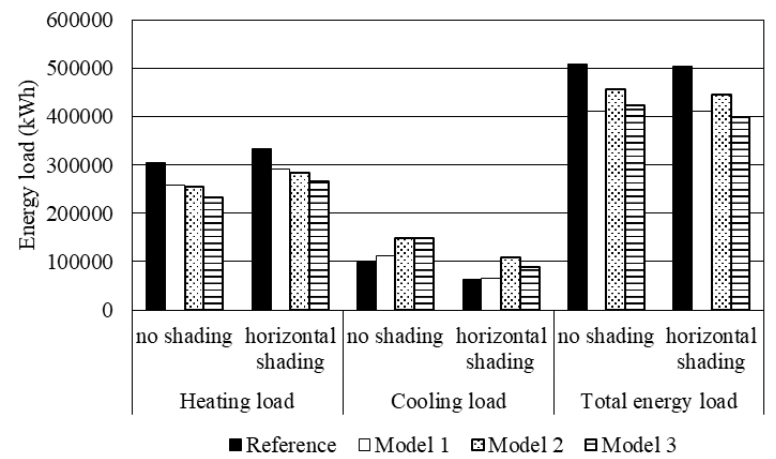

Fig. 6. Yearly energy loads in all office models with horizontal shading device and no shading

In Fig. 6, it was concluded that the use of a shading device increases heating loads and decreases cooling loads. As the reduction in cooling loads is higher than the increase in heating loads, the total energy load is reduced in all models when the shading device is used. Table 6 shows the change in the performance of energy loads as a percentage according to the reference office model in all office models for two cases where the shading device is used and not used. When this table is examined, it is seen that it is possible to improve the cooling load in the range of $38 \%-60 \%$ by using the shading device on all models, while the improvement in the total energy load remains within the range of $2-5 \%$. This is due to the increase in heating loads.

\subsection{Comparison of the overall energy performance of the models}

In this section, the parameters are kept constant to compare the overall energy performance of the models. When the moderate-humid climate region is taken into consideration, the performance comparison according to heating, cooling and total energy loads of office models with clear double glazing system is given in Fig. 7. It shows that the cooling loads are higher than the reference model in all models. In terms of heating load, Model 3, Model 2 and Model 1 respectively shows the best performance. When the total energy load is taken into account, it is seen that the order changes as Model 1, Model 3 and Model 2.

In Fig. 8, the results obtained for moderatehumid climate region are evaluated and the contribution to energy performance as a percentage of glazing system type and the use of shading device in investigated models in terms of the total energy load is given. It shows that the performance of the model increased by $11 \%$ to $19 \%$ in terms of total energy load by adding a courtyard or atrium to the reference model without the shading device with DCLR glazing system. 
Table 6. Comparing energy load performances of all models with no shading and horizontal shading device as a percentage according to the reference model

\begin{tabular}{|c|c|c|c|c|c|c|}
\hline & \multicolumn{2}{|c|}{ Heating load } & \multicolumn{2}{|c|}{ Cooling load } & \multicolumn{2}{|c|}{ Total energy load } \\
\hline & no shading & $\begin{array}{l}\text { horizontal } \\
\text { shading }\end{array}$ & no shading & $\begin{array}{l}\text { horizontal } \\
\text { shading }\end{array}$ & no shading & $\begin{array}{c}\text { horizontal } \\
\text { shading }\end{array}$ \\
\hline Reference & $*$ & $-9 \%$ & $*$ & $+38 \%$ & $*$ & $+2 \%$ \\
\hline Model 1 & $+16 \%$ & $+5 \%$ & $-11 \%$ & $+34 \%$ & $+19 \%$ & $+19 \%$ \\
\hline Model 2 & +17 & $+7 \%$ & $-48 \%$ & $-8 \%$ & $+11 \%$ & $+13 \%$ \\
\hline Model 3 & $+24 \%$ & $+13 \%$ & $-49 \%$ & $+11 \%$ & $+17 \%$ & $+22 \%$ \\
\hline
\end{tabular}

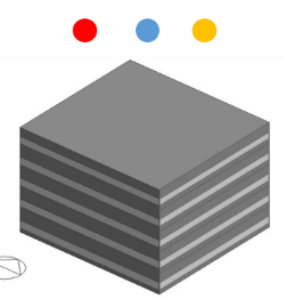

Reference model

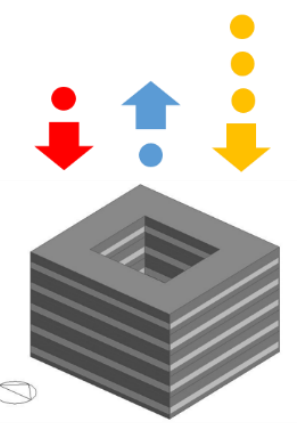

Model 1

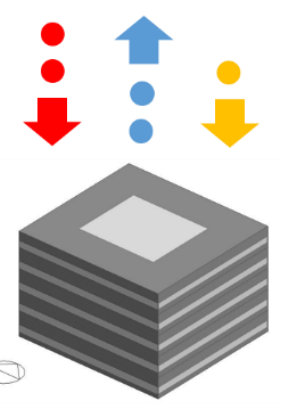

Model 2

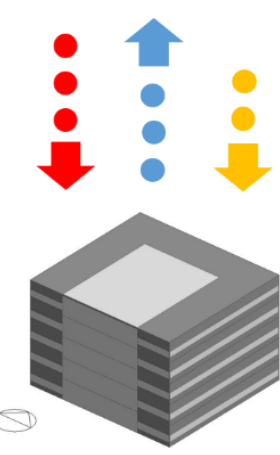

Model 3

Heating load

Cooling load

Total energy load

Fig. 7. Comparison of heating, cooling and total energy loads of investigated office models in moderate-humid climate region

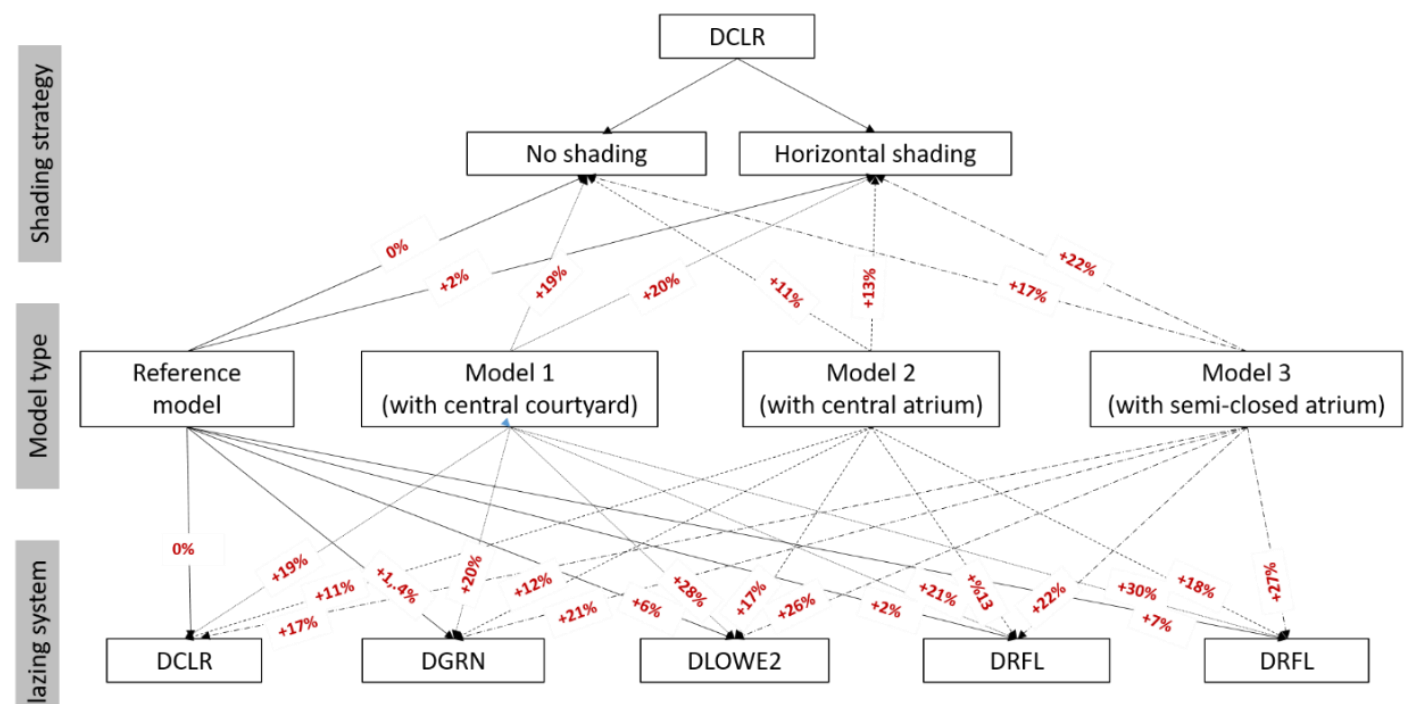

Fig. 8. Change of their performances in terms of total energy loads provided through energy renovations applied on all models in moderate-humid climate as percentage 
The energy performance of the reference model has been increased by $1.4 \%$ to $30 \%$ across all models. The use of shading device resulted in a performance increase of $2 \%-22 \%$.

\section{Conclusions}

In this study, three office building model with central courtyard, central atrium, and a semi-closed atrium were created from a hypothetical office building that is accepted as a reference model in moderate-humid, hot-humid and cold climate region of Turkey. In all models, floor areas were kept constant. Firstly, the heating, cooling and total energy loads of all models in all climatic regions were calculated and the percentage changes in energy performances according to the reference performance were determined. After discussing the effects of climate on each building model, it was explored how the energy performance of these models could be improved and how different types of double glazing systems usage, window-to-wall ratio change, and use of shading device could contribute to the energy performance of the models. The results were listed below.

- In all climate regions, it was observed that the lowest heating load according to the reference model with DCLR in Model 3 with semi-closed atrium. It does not have a central courtyard and this is an advantage for moderate-humid climate regions. Providing more natural light compared to the reference model, it was seen as an advantage for each climate region in terms of lighting saving.

- In terms of cooling load, all models with courtyard and atrium showed worse performance than the reference model in all climate region. Thus, cooling loads were increased in these models.

- In terms of total energy load, while Model 1 has the best performance in moderate-humid and hot-humid climate regions, Model 3 shows the best performance in cold climate region

- The ratio of heating and cooling load to total load in each climate region has changed. In the cold climate region and moderate-humid climate region, the heating load was the dominant load, while the cooling load was dominant in the hot-humid climate region.

- In all of the investigated models, the change of the clear double glazing system (DCLR) with heat preservation and solar control glazing systems caused the performance of the models to change according to the climate regions. When the moderate-humid climate region is taken into consideration, there is no positive change in the heating loads due to the fact that the investigated glazing systems are largely solar control glazing systems. But, it was observed cooling load is substantially reduced. This decrement affected total energy loads as positive and improvement in the range of $1 \%$ to $11 \%$ in the total energy load is achieved in all models.

- It is necessary to take into account the total energy load when making recommendations according to climate regions. Because the expenses that will be spent during the life span of that building are evaluated over the total energy consumption.

- In the investigated models, increasing the transparent surface areas had a negative effect on the total energy load. However, it increased the use of natural light due to the reduction of lighting energy consumption. Considering the positive effects of the use of the shading device, it is clear that increasing the transparent surface area will make a significant contribution with the selection of the suitable glazing systems and the use of adequate shading device.

- The cooling loads are higher than the reference model in all models. In terms of heating load, Model 3, Model 2 and Model 1 respectively shows the best performance. When the total energy load is taken into account, it is seen that the order changes as Model 1, Model 3 and Model 2.

- The performance of the model increased by $11 \%$ to $19 \%$ in terms of total energy load by adding a courtyard or atrium to the reference model without the shading device with DCLR glazing system. The energy performance of the reference model has been increased by $1.4 \%$ to 
$30 \%$ across all models. The use of shading device resulted in a performance increase of $2 \%$ $-22 \%$.

Currently, the use of atrium is becoming increasingly common in commercial high-rise buildings. It is very important to design the atrium to increase the daylight entering the interior spaces according to the climatic conditions. If the correct measures are not taken, the use of atrium may adversely affect energy consumption. Therefore, in the early design phase of buildings, the type and size of the atrium, its direction, the glazing system and the shading device to be used in the atrium should be considered as a priority.

Considering all these evaluations, atrium types that can be ignored or not in this study can be examined for different climatic and building types. Daylight performance as well as thermal energy performance of identified scenarios can be investigated. CFD simulations can be conducted to evaluate natural ventilation behavior. In all these studies, statistical methods can be used by considering user comfort and evaluations in order to reach optimum results.

\section{References}

[1] IEA, (2019). International Energy Agency. Energy Efficiency: Building (The Global Exchange for Energy Efficiency Policies, Data and Analysis). https://www.iea.org/topics/energyefficiency/buildi ngs/. Accessed: 20.02.2019.

[2] Laouadi A, Atif MR, Galasiu A (2002). Towards developing skylight design tools for thermal and energy performance of atriums in cold climates. Building and Environment, 37(12), 1289-1316.

[3] Abdullah AH, Meng Q, Zhao L, Wang F (2009). Field study on indoor thermal environment in an atrium in tropical climates. Building and Environment, 44(2), 431-436.

[4] Hung WY (2003). Architectural aspects of atrium. International Journal on Engineering PerformanceBased Fire Codes, 5(4), 131-137.

[5] Bahadır Ü, Thomollari X, Toğan V (2018). Evaluation of energy-cost efficient design alternatives for residential buildings. Journal of Construction Engineering, Management \& Innovation, 1(1), 43-54.
[6] Sher F, Kawai A, Güleç F, Sadiq H (2019). Sustainable energy saving alternatives in small buildings. Sustainable Energy Technologies and Assessments, 32, 92-99.

[7] Ghasemi M, Kandar M.Z, Noroozi M, Yazdipour F, Namaziyan S, Roshan M (2013). Capability of computer simulation software for predicting average daylight factors in a vertical top-light atrium. J. Basic Appl. Sci. Res, 3(11), 96-105.

[8] Saxon R (1983). Atrium Buildings: Development and Design. London: Architectural Press.

[9] Aldawoud A (2013). The Influence of the Atrium Geometry on the Building Energy Performance. Energy and Buildings, 57, 1-3.

[10] Huang Y, Borong L, Yao N, Yingxin Z (2015). Functional relationship between lighting energy consumption and the main parameters for double atrium offices. Procedia Engineering, 121, 1869 1879.

[11] Vujosevic M, Krstic-Furundzic A (2017). The influence of atrium on energy performance of hotel buildings. Energy and Buildings, 156, 140-150.

[12] Lan W, Qionga H, Qia Z, Hong X, Yuen RK (2017). Role of atrium geometry in building energy consumption: The case of a fully air-conditioned enclosed atrium in cold climates, China. Energy and Buildings, 151, 228-241.

[13] Moosavi L, Mahyuddin N, Ghafar N (2015). Atrium cooling performance in a low energy office building in the tropics, a field study. Building and Environment, 94, 384-394.

[14] Moosavi L, Mahyuddin N, Ab Ghafar N, Ismail MA (2014). Thermal performance of atria: An overview of natural ventilation effective designs. Renewable and Sustainable Energy Reviews, 34, 654-670.

[15] Pfafferott J, Herkel S, Wambsganß M (2004). Design, monitoring and evaluation of a low energy office building with passive cooling by night ventilation. Energy and buildings, 36(5), 455-465.

[16] Göçer Ö, Tavil A, Özkan E (2006). Thermal performance simulation of an atrium building. In Proceedings of eSim building performance simulation conference. Faculty of architecture, landscape, and design. University of Toronto, Canada, 33-40.

[17] Aldawoud A, Clark R (2008). Comparative analysis of energy performance between courtyard and atrium in buildings. Energy and Buildings, 40(3), 209-214. 
[18] Ab Ghafar N, Gadi M, Adam M (2019). Evaluation of thermal and solar performance in atrium buildings using sequential simulation. Energy \& Environment. DOI: 10.1177/0958305X18813684.

[19] Aram R, Alibaba HZ (2019). Thermal comfort and energy performance of atrium in mediterranean climate. Sustainability, 11(4), 1213.

[20] Vethanayagam V, Abu-Hijleh B (2019). Increasing efficiency of atriums in hot, arid zones. Frontiers of Architectural Research, https://doi.org/10.1016/j. foar.2019.05.001

[21] Danielski I, Nair G, Joelsson A, Fröling M (2016). Heated atrium in multi-storey apartment buildings, a design with potential to enhance energy efficiency and to facilitate social interactions. Building and Environment, 106, 352-364. 